\title{
EFEITO DE COMBINAÇÕES DE VERMICULITA E VERMICOMPOSTO NO DESENVOLVIMENTO DE PORTA-ENXERTO DE LIMÃO CRAVO
}

\author{
ORIOLI, Fabrício Alberghini ${ }^{1}$ \\ ORIOLI JÚNIOR, Valdeci ${ }^{2}$ \\ OLIVEIRA, Antônio Luís de ${ }^{3}$
}

\begin{abstract}
RESUMO: O presente trabalho foi conduzido em ambiente protegido, localizado na Estância Santa Luzia, situada no município de Monte Azul Paulista - SP. Foi avaliado o desenvolvimento de porta-enxerto de limão cravo em diferentes combinações de vermiculita e vermicomposto. O delineamento estatístico utilizado foi inteiramente casualizado, com cinco repetições, composto por sete tratamentos: $100 \%$ vermiculita; $100 \%$ húmus; $50 \%$ vermiculita e $50 \%$ húmus; $60 \%$ vermiculita e $40 \%$ húmus; $70 \%$ vermiculita e $30 \%$ húmus; $80 \%$ vermiculita e $20 \%$ húmus; $90 \%$ vermiculita e $10 \%$ húmus. Foram avaliadas a massa verde, a massa seca e a altura de plântulas aos 60 dias, após a semeadura. Não houve diferença entre as combinações testadas e o efeito da vermiculita foi idêntico ao do húmus.
\end{abstract}

Palavras-chave: Citricultura, substrato, Citrus limonia Osbeck, húmus.

\section{EFFECT OF COMBINATIONS OF VERMICULITE AND EARTHWORM COMPOST IN THE DEVELOPMENT OF RANGPUR LIME ROOTSTOCK}

\begin{abstract}
The present work was done in protected environment, located in the Ranch Saint Luzia, situated in Monte Azul Paulista city. Rangpur lime rootstock was evaluated in different combinations of vermiculite and earthworm compost. The experiment was installed using a randomized block design, with five repetitions and seven treatments: $100 \%$ vermiculite; $100 \%$ earthworm compost; $50 \%$ vermiculite and 50\% earthworm compost; $60 \%$ vermiculite and $40 \%$ earthworm compost; $70 \%$ vermiculite and 30\% earthworm compost; $80 \%$ vermiculite and $20 \%$ earthworm compost; $90 \%$ vermiculite and 10\% earthworm compost. It was also evaluated the green matter, the dry matter and seedlings height afther 60 days of seeding. There was no difference between the tested combinations and the effect of the vermiculite was identical to the earthworm compost.
\end{abstract}

Key words: Citriculture, substrate, Citrus limonia Osbeck, earthworm compost.

\section{INTRODUÇAO}

A citricultura brasileira encontra-se atualmente, em posição relevante, ocupando o primeiro lugar na produção mundial de frutas frescas, assim como uma maior receita entre os países exportadores de suco concentrado congelado. Porém, a produção de frutos cítricos não se baseia em altos índices de produtividade, mas na expansão das áreas de plantio.

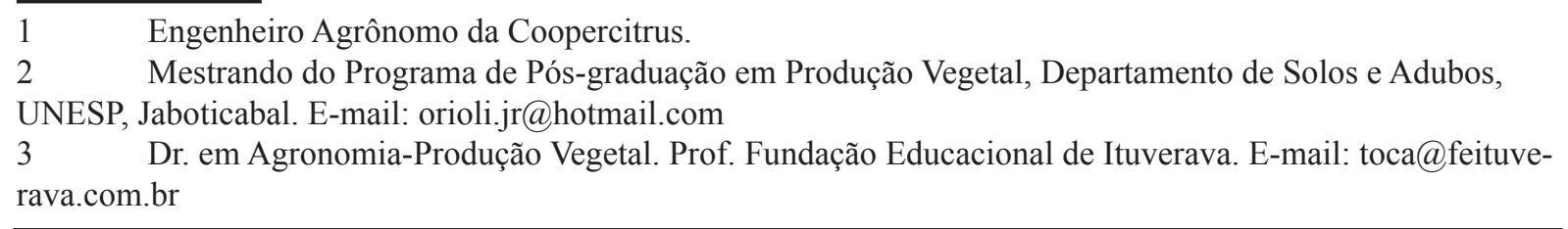


A cultura de citros é de um ciclo de vida muito longo, sendo, portanto, de extrema importância a utilização de mudas sadias, vigorosas, de crescimento rápido e portadoras de uma rizomassa bem desenvolvida, para se obter os resultados desejados durante todo o ciclo da planta.

Assim, sendo a produtividade de um pomar depende, em grande parte, da qualidade da muda usada na sua implantação. O primeiro passo para a obtenção de mudas de boa qualidade seria a produção de porta-enxertos vigorosos em curto espaço de tempo, para que haja um retorno econômico rápido do capital investido. Para isso, torna-se necessário um bom fornecimento de nutrientes e uso de substratos com características físicas adequadas.

Em sistemas de produção de mudas de citros envasadas, já utilizados em vários países, inclusive no Brasil, pode-se produzir a muda de 10 a 15 meses após a semeadura (CARVALHO et al., 2005). Atualmente, o sistema de produção de mudas cítricas, a campo, no Rio Grande do Sul, desde a sementeira até a comercialização, leva 36 meses. Com a utilização de cultivo em ambiente protegido, recipientes e substratos adequados, desde o início, ou seja, desde a produção dos porta-enxertos, este tempo pode ser reduzido em até 50\% (JOÃO, 1999).

Dois materiais muito utilizados no Brasil como substratos são a vermiculita e o húmus (vermicomposto). A vermiculita é um mineral de baixa densidade, constituído de lâminas justapostas, além de tetraedros e octaedros de ferro e magnésio que, quando submetida a aquecimento, expande-se, consideravelmente, pelo aumento do espaço entre suas camadas, apresentando com isso, alta capacidade de retenção de água, ar e nutrientes disponíveis às plantas. Isso faz com que esse material seja muito estudado na composição de substratos para produção de mudas em recipientes (GRIM, 1968).

Segundo Raviv (1988), o húmus, por ser mal condutor de calor, atenua a amplitude térmica do substrato e, ainda, tem maior capacidade de troca cationica que as argilas, por estar em estado amorfo e possuir maior superfície especifica que as mesmas. Com isso, o húmus possui grande poder tampão e, também, por certos compostos orgânicos se ligarem a íons metálicos como ferro, manganês, zinco e cobre, complexando-os (quelação), pode fornecer esses metais paulatinamente, à medida que as plantas necessitem.

Já em 1998, a bibliografia citava que, no mercado nacional, estavam disponíveis diferentes substratos, obtidos a partir de misturas de diferentes materiais, indistintamente recomendados a um grande número de espécies, cujas formulações e características eram pouco conhecidas e cujos desempenhos, como meio de cultivo, poderiam ser irregulares (MENEZES JÚNIOR; FERNANDES, 1998). Atualmente, existem grandes empresas produtoras de substrato, muitos deles específicos para diferentes fases de produção de mudas para grandes culturas, como ocorre com a produção de mudas cítricas. Entretanto, a preocupação com a qualidade dos materiais ainda deve ser constante.

Nesse contexto, o objetivo do trabalho foi avaliar o desenvolvimento da parte aérea de porta-enxertos de limão "Cravo" por meio de algumas características morfológicas em diversas combinações de vermiculita e vermicomposto. 


\section{MATERIAL E MÉTODOS}

O experimento foi conduzido na Estância Santa Luzia, situada no município de Monte Azul Paulista - SP, sob telado de $1 \mathrm{~mm}$ e 50\% de luminosidade, com início em 03/08/1998. A cidade está situada a $20^{\circ} 54^{\prime} 23^{\prime \prime}$ de latitude sul e $48^{\circ} 38^{\prime} 29^{\prime \prime}$ de longitude oeste, a uma altitude de $611 \mathrm{~m}$.

Os tratamentos constaram de sete tipos de substratos, sendo que cinco deles foram combinações de vermiculita e húmus (vermicomposto), que são citados a seguir: 100\% vermiculita; $100 \%$ húmus; $50 \%$ vermiculita $+50 \%$ húmus; $60 \%$ vermiculita $+40 \%$ húmus; $70 \%$ vermiculita $+30 \%$ húmus; $80 \%$ vermiculita $+20 \%$ húmus; $90 \%$ vermiculita $+10 \%$ húmus.

A semeadura foi realizada em tubetes cônicos de 3,00 cm de diâmetro na parte superior, $15 \mathrm{~cm}$ de altura e $1 \mathrm{~cm}$ na parte inferior, com capacidade para $75 \mathrm{~mL}$ de substrato. Foram colocadas 4 sementes por tubete, com a finalidade de deixar apenas uma planta por tubete, procurando-se escolher a maior e mais vigorosa.

O delineamento utilizado foi inteiramente casualizado, composto pelos sete tratamentos já descritos, com 5 repetições e 20 plantas por parcela, portanto, 700 plantas a serem avaliadas.

Para adubação de plantio, foram adicionados $300 \mathrm{~g}$ do adubo de liberação gradual Osmocote por 100 L de substrato (19-06-10/ liberação de três a quatro meses). A adubação de cobertura iniciou-se aos 30 dias após a semeadura, sendo utilizada a fórmula 10-10-10 em dias alternados, com nitrocálcio $(22 \% \mathrm{~N}$ e $18 \% \mathrm{Ca})$, em forma de fertirrigaçao, no volume de $1 \%$. A aplicação de micronutrientes foi realizada por pulverizações com: $\mathrm{Mg}-1 \%, \mathrm{Mn}-2 \%, \mathrm{~B}$ $-0,5 \%, \mathrm{Zn}-3 \%$ e S $-3 \%$.

Após a germinação, realizaram-se pulverizações semanais, alternadas com benomyl a $0,1 \%$, oxicloreto de cobre a $0,1 \%$ e thiophanate methyl (Cercobin).

$\mathrm{O}$ desbaste foi realizado quando as plantas atingiram três pares de folhas definitivas e, como dito, procurou-se deixar as maiores e mais vigorosas.

A irrigação foi realizada duas vezes ao dia, sendo uma pela manhã e outra no horário de pico de temperatura no ambiente protegido, com a finalidade de reduzir a temperatura e fornecer água.

Aos 60 dias após a semeadura, fez-se avaliação destrutiva das mudas, que foram lavadas e, em seguida, medidas do coleto até a última folha. Depois de lavado em água destilada, o material foi pesado em balança de precisão, com o intuito de se determinar a massa verde da parte aérea das plântulas; posteriormente, foi acondicionado em sacos de papel e seco em estufa com circulação forçada de ar à temperatura de $60-70^{\circ} \mathrm{C}$, até atingir peso constante, para assim determinar-se a massa seca da parte aérea das plântulas também em balança de precisão.

Os dados foram submetidos à análise de variância, de acordo com Banzatto e Kronka (1989) e, na comparação das médias, foi utilizado o teste de Tukey a 5\% de probabilidade. 


\section{RESULTADOS E DISCUSSÃO}

Os resultados referentes às características morfológicas avaliadas estão apresentados na Tabela 1.

Tabela 1: Valores médios obtidos para massa verde da parte aérea, massa seca da parte aérea, umidade e altura de plântulas de limão cravo em função do tipo e combinação de substratos.

\begin{tabular}{lccc}
\hline \hline \multicolumn{1}{c}{ Tratamentos } & $\begin{array}{c}\text { Massa verde }(\mathrm{g} / \\
\text { planta })\end{array}$ & $\begin{array}{c}\text { Massa seca }(\mathrm{g} / \\
\text { planta })\end{array}$ & Altura $(\mathrm{cm})$ \\
\hline $100 \%$ vermiculita & $1,4886 \mathrm{a}$ & $0,3143 \mathrm{a}$ & $10,9286 \mathrm{a}$ \\
$100 \%$ húmus & $1,4000 \mathrm{a}$ & $0,3171 \mathrm{a}$ & $11,5714 \mathrm{a}$ \\
$50 \%$ vermiculita $+50 \%$ húmus & $1,8871 \mathrm{a}$ & $0,3686 \mathrm{a}$ & $11,0000 \mathrm{a}$ \\
$60 \%$ vermiculita $+40 \%$ húmus & $1,5543 \mathrm{a}$ & $0,3029 \mathrm{a}$ & $10,2143 \mathrm{a}$ \\
$70 \%$ vermiculita $+30 \%$ húmus & $1,8600 \mathrm{a}$ & $0,3814 \mathrm{a}$ & $12,2143 \mathrm{a}$ \\
$80 \%$ vermiculita $+20 \%$ húmus & $1,3943 \mathrm{a}$ & $0,2929 \mathrm{a}$ & $11,2143 \mathrm{a}$ \\
$90 \%$ vermiculita $+10 \%$ húmus & $0,9314 \mathrm{a}$ & $0,2100 \mathrm{a}$ & $9,6429 \mathrm{a}$ \\
\hline \multicolumn{1}{c}{$\mathrm{CV}(\%)$} & 15,2 & 12,8 & 15,4 \\
\hline \hline
\end{tabular}

Médias seguidas pelas mesmas letras nas colunas não diferem ao nível de $5 \%$ de probabilidade.

Nota-se, que para todos os parâmetros considerados, não houve efeito significativo em função do tipo de substrato e das combinações testadas.

Os resultados de massa verde da parte aérea discordam dos obtidos por Jabur (2001) que, também trabalhando com diferentes composições de vermiculita e húmus, notou que o tratamento constituído de $50 \%$ de vermiculita $+50 \%$ húmus proporcionou maiores valores de massa verde de plântulas em relação ao substrato composto somente por vermiculita, não diferindo, contudo, dos demais tratamentos. Embora o tratamento $50 \%$ de vermiculita $+50 \%$ de húmus não tenha diferido dos demais, uma análise mais acurada dos dados obtidos para a massa fresca da parte aérea indicam destaque para esse tratamento.

Quanto à massa seca da parte aérea, os resultados diferem dos descritos por Cabrera (2004) que, nos tratamentos que utilizaram vermicomposto (mistura $50 \%$ ou $100 \%$ ), os resultados foram distintamente superiores ao observado nas mudas que utilizaram somente o substrato comercial (Plantmax). Jabur (2001) também relatou diferenças para essa variável quanto aos substratos utilizados, verificando que a mistura de $50 \%$ de vermiculita $+50 \%$ de húmus proporcionou maior acúmulo de massa seca da parte aérea e que a utilização de $100 \%$ de vermiculita acarretou valores menores.

Os valores de massa seca da parte aérea observados se mostraram aquém dos obtidos por Carvalho (1994) e por Lira (1990), porém foram semelhantes aos de Jabur (2001) e acima dos relatados por Joaquim (1991). Provavelmente, essas diferenças existem devido à composição de cada substrato e ao volume dos recipientes utilizados.

Já os dados referentes à altura de plantas concordam com os obtidos por Jabur (2001), que, também, não notou diferença em função das diferentes composições do substrato. No entanto, 
a altura mínima de repicagem $(10 \mathrm{~cm})$, sugerida por Grassi Filho et al. (2001), já foi alcançada aos 60 dias após a semeadura, diferindo do mesmo autor anteriormente citado, que verificou serem necessários 111 dias após a semeadura, para as plântulas atingirem a altura mínima de repicagem. Araújo et al. (2006) observaram que o substrato, contendo apenas húmus, propiciou plântulas mais altas em relação ao substrato composto apenas por vermiculita. Cabrera (2004) também observou que a altura das mudas, nos tratamentos que utilizaram vermicomposto (mistura $50 \%$ ou 100\%), foi, distintamente, superior ao observado nas mudas que utilizaram somente o substrato comercial (Plantmax); sendo, portanto, discordantes dos obtidos nesse ensaio.

No entanto, apesar de não terem ocorrido diferenças estatísticas, uma análise conjunta dos parâmetros avaliados sugere que os substratos que continham 50 ou $30 \%$ de húmus propiciaram melhores resultados, o que demonstra a importância de cada componente na mistura, tendo talvez, o húmus, propiciado melhores condições físicas para o substrato, favorecendo o crescimento das plântulas.

Os resultados ainda indicam que o húmus pode trazer vantagens à produção de portaenxertos, devido ao seu menor custo em relação à vermiculita, contudo, além do aspecto econômico, devem-se considerar aspectos fitossanitários na utilização desse tipo de substrato.

\section{CONCLUSÃO}

De acordo com os dados obtidos, pode-se concluir que:

- O efeito do húmus e vermiculita, assim como o das combinações entre os dois são iguais no desenvolvimento de plântulas de limão cravo aos 60 dias após a semeadura.

- Os aspectos econômicos e fitossanitários devem ser considerados na escolha do substrato.

\section{REFERÊNCIAS}

ARAÚJO, P.O.L.C. et al. Crescimento e percentual de emergência de plântulas de citrumeleiro swingle em função dos substratos e das doses de corretivo à base de lithothamnium, após cem dias da semeadura. Ciência e Agrotecnologia. Lavras, v.31, n.4, p.982-988, 2007.

BANZATTO, D.A.; KRONKA, S.N. Experimentação Agrícola. Jaboticabal: Funep, 1989. $247 \mathrm{p}$.

CABRERA, R.A.D. Produção de mudas cítricas em viveiro: uso de substrato alternativo e inoculação com Xylella fastidiosa. Piracicaba: Escola Superior de Agricultura Luiz de Queiroz, 2004. 106f. Dissertação (Mestrado em Ecologia e Agroecossitemas) - Escola Superior de Agricultura Luiz de Queiroz, Piracicaba, 2004. 
CARVALHO, S.A. et al. Produção de material básico e propagação. In: MATTOS JÚNIOR, D. et al. Citros. Campinas: Instituto Agronômico e Fundag, 2005. p.281-311.

CARVALHO, S.A. Manejo da adubação nitrogenada na produção de porta-enxertos cítricos em bandejas. Lavras: Escola Superior de Agricultura de Lavras, 1994. 74f. Tese (Doutorado em Agronomia) - Escola Superior de Agricultura de Lavras, Lavras, 1994.

GRASSI FILHO, H. et al. Efeito de diferentes substratos no crescimento de mudas de limoeiro Cravo até o ponto de enxertia. Revista Laranja, Cordeirópolis, v.22, n.1, p.157-166, 2001.

GRIM, R.E. Clay mineralogy. New York: McGraw Hill, 1968. 596 p.

JABUR, M.A. Influência de substratos na formação dos porta-enxertos: limoeiro Cravo (Citrus limonia Osbeck) e Tangerineira Cleópatra (Citrus reshni Hort. Ex Tanaka) em ambientes protegidos. 2001. 54 f. Tese (Doutorado em Agronomia) - Faculdade de Ciências Agrárias e Veterinárias, Universidade Estadual Paulista, Jaboticabal, 2001.

JOAQUIM, D. Avaliação de três substratos para semeadura de limoeiro Cravo (Citrus limonia, Osbeck), laranjeira Caipira (Citrus sinensis L. Osbeck) e tangerineira Cleópatra (Citrus reshni, Hort. Ex. Tan.) em bandejas. Jaboticabal: Universidade Estadual Paulista, 1991. 133f. Dissertação (Mestrado em Agronomia) - Faculdade de Ciências Agrárias e Veterinárias. Universidade Estadual Paulista, Jaboticabal, 1991.

JOÃO, P.L. Procedimientos y problemática para la implantación de um programa de certificación de cítricos en el Estado de Rio Grande do Sul - Brasil. Valência-Espanha: Universidade Politécnica de Valência - Instituto Valenciano de Investigaciones Agrarias, 1999. 97p.

LIRA, L.M. Efeito de substratos e do superfosfato simples no limoeiro cravo (Citrus limonia cv. Cravo) até a repicagem. Lavras: Escola Superior de Agricultura de Lavras, 1990. 85f. Dissertação (Mestrado em Agronomia) - Escola Superior de Agricultura de Lavras, Lavras, 1990.

MENEZES JÚNIOR, F.O.G.; FERNANDES, H.S. Substratos formulados com vermicomposto e comerciais na produção de mudas de couve-flor. Revista Brasileira de Agrociência. Pelotas, v.4, n.3, p.191-196, 1998.

RAVIV, M. Horticulture uses of composted material. Acta Horticulturae. Leiden, n.469, p.225-234, 1988. 